cation with the lead. The current, inducted by a special arrangement of the circuit which is as simple as it is original (both at the transmitter and receiver
ends) is transformed into a vibratory pulsating current; at the receiving station it reaches a coherer of special construction and causes the operation of any suitable telegraphic apparatus, using either Morse sig. nals or printing signs, etc., on the Hughes principle. This coherer (which is apparently directly opposed to all coherers hitherto known) establishes or breaks its coherency with rapidity and certainty; once placed in operation it continues to work with perfect precision, all the drawbacks (such as excessive sensitiveness, always causing great variability) common to other types so far known having been successfully done away with. This new coherer will, therefore, be of great value for use in connection with wireless telegraphy.

Although only a few volts are used at the transmitting station, and while there are only two dry cells at the receiving center, still messages can be safely forwarded over distances amounting to hundreds of miles; hence with the new Magini system the use of cumbersome and expensive batteries of cells or accumulators at telegraphic stations becomes a thing of the past.

The new system practically admits of duplex telegraphy, without recourse to the actual complicated means employed-means which necessitate scientific and special technical knowledge on the part of the employes and which, furthermore, are exposed to all those multiple causes which induce modifications in the electric condition of the wires, thus necessitating the electric condition of the wires, thus necessitating
continual variation and readjustment of the electric accord existing between the different offices or stations. When mounted in derivation on the two extremes of an electric wire, Magini's transmitter and receiver do not necessitate any alteration in existing plant, and two different messages can also be sent over the same wire at one and the same time.

A further, and very valuable, application of this system lies in its applicability to use in submarine work; not only does it double the power of the cable, but it also enables two messages to be sent together over one and the same cable.

The high charges made for sending telegrams over long submarine cables is due to their low capacity, when considered in proportion to time and to the large amount of capital invested therein. The possibility of doubling their present capacity, and of transmitting two messages at once, hence will be equivalent to reducing the present charges for cables by one-half.

As the currents employed by Magini have the peculiar property of being able to jump over gaps or breaks in the leads and continue their journey undisturbed, this gentleman has been able to maintain uninterrupted communication over wires and cables, the inner core or conductor of which has been broken-i. e. under conditions with which existing methods would have been entirely unable to cope. Consequently, should a submarine cable become worn out, or unserviceable for any other reason (e. g., accidental breakage of the core during laying, infiltration of sea water and consequent rusting due to electrolysis, et hoc genus omne), telegraphic communication can nevertheless be kept up with Magini's system until the long and costly operations of fishing up and repairing the cable are completed.

\section{THE EFFECT OF HYDROGEN ON GAS ENGINE COMPRESSION.}

\section{BY GEORGE M. S. TAIT.}

As many are aware, one of the main difficulties encountered in the steady performance of a producer-gasoperated gas engine is caused by the fluctuation in the quality of the gas generated by the producer, and as a proof of this we have all noticed the excellent performances obtained from gas engines operating on illuminating or natural gas, of a fixed analysis, as compared with the somewhat varying runs obtained with the same engines when operating on producer gas. This absence observed in the operation of the engine is more noticeable in conjunction with the suction type of producer where no gas holder is employed, the reason for this being that momentary variations which always occur in the present type of producer are not
felt so much where a large gas holder is employed, as the lean gas has an opportunity for mixing with the other gas already in the holder, with the result that the supply drawn by the engine is more or less of a constant quality.

In acknowledging, therefore; that the quality of producer gas varies, our next step is to ascertain the cause of this variation and to indicate if possible a remedy therefor.

The theoretical analysis of producer gas made from anthracite coal would be about as follows:

$$
\begin{aligned}
& \text { CO } \ldots \ldots \ldots \ldots \ldots 27.0 \text { per cent by volume. } \\
& \mathrm{H} \ldots \ldots \ldots \ldots \ldots \ldots \ldots \ldots \ldots \ldots \ldots \text { per cent by volume. } \\
& \mathrm{CH}_{4} \ldots \ldots \ldots \ldots \ldots, 1.2 \text { per cent by volume. } \\
& \mathrm{CO}_{2} \ldots \ldots \ldots \ldots \ldots .2 .5 \text { per cent by volume. } \\
& \begin{array}{l}
57.0 \text { per cent by volume. } \\
0.3 \text { per cent by volume. }
\end{array}
\end{aligned}
$$

Unfortunately, however, in practice the quantity of CO will be found to be much lower than the above, while $\mathrm{CO}_{2}$ and $\mathrm{H}$ will correspondingly increase. This change in the gas is, however, not shown by the usual calorimeter test, due partly to the fact that as the CO decreases it is offset as far as heating value goes by the increase of $\mathrm{H}$; this increase sometimes causes a rise in B. T. U. above the figures first mentioned.

However, a gas high in B. T. U. is not necessarily a good gas for engines, especially if by this increase we have to sacrifice high compression in order to guard against pre-ignition; and as, in the case of the present producers, high B. T. U. generally means a high percentage of $\mathrm{H}$, this increase in heating value proves to be rather a detriment than otherwise to the engine performance.

The engine builder is aware that his compression must be governed by the maximum amount of hydrogen which his engine is liable to encounter at any time during the run, and he therefore is forced to put the compression much lower than he otherwise would do in order to safeguard himself against pre-ignitions. I would appear, therefore, that if a gas sufficiently rich, but at the same time having little or no $H$, could be manufactured, ideal results would be obtained.

That this is the case has been demonstrated by the wonderful results obtained in Europe from gas en gines operating on blast furnace gas, which, althoug of a very low heating value, are free from $\mathrm{H}$ and consequently admit of a very high compression on the engines. In support of this argument it is interestin to note that gas engines are now operating on 9,500 B. T. U. and even lesss per brake horse-power on this gas, where the compression has been raised to 200 pounds, whereas the same make of engines operatin on producer gas of a richer quality, but containing $\mathrm{H}$ are found to consume from 11,000 to $12,500 \mathrm{~B}$. T. U. pe brake horse-power, but with a compression of onl 130 pounds. The present outfit for the manufacture of producer gas comprises a producer, scrubber, purifier, and in some cases a gas storage tank or holder. The fuel is burned incompletely in the producer either by forced or induced draft, the resulting gas passing off forced or induced

No the engines.
Now in practice it is found that the fuel bed would Now in practice it is found that the fuel bed would condition would cause undue clinkering of the fuel as well as a lean gas, there is introduced steam or water vapor along with the incoming air for the double object of lowering the temperature of the fire by the heat absorbing property of the steam, and in cases wher the temperature is high enough the dissociation of sai steam or water vapor occurs, the oxygen uniting with the carbon of the coal to form CO while the $\mathrm{H}$

The one defective feature of this system is that the percentage of $\mathrm{H}$ is continually changing, owing to the varying temperatures of the fire, which at one time is too cool to decompose the steam and merely allows the same to pass through the fuel bed in a superheate condition; while at other times when the demand for gas is greater and the rate of combustion consequently higher the resultant rise in temperature dissociates the steam, making a variation in all of from 5 to 20 per cent of $\mathrm{H}$ in the gas by volume.

The engine builder, being aware of this unknown quantity in the form of $\mathrm{H}$ upon which his engine ha to operate, is compelled to sacrifice high compressio and the incident economies therefrom in order to guard against pre-ignitions and to lower the compression so that the working efficiency of the plant is very much impaired.

That the compression at which the engine operates has a powerful effect on the economy of the plant is well set off by the performances of a certain wellknown make of engine on producer gas containing hydrogen, and blast furnace gas containing no hydrogen, as follows: In the first instance the engine, the compression of which was set to 120 pounds, uses 11,500 B. T. U. per brake horse-power per hour, while in the second instance engines of the same make with a compression of from 170 to 200 pounds are operating steadily on 9,500 B. T. U. per brake horse-power.

This enormous saving accomplished solely by increasing the compression, is very obvious, and when it is realized that these results are only possible wher $\mathrm{H}$ is eliminated from the gas it would seem that producer which would supply a gas sufficiently high in CO to obviate the necessity of too large a cylinde would give ideal results in engine practice.

Having this object in view, producer manufacturers have long been experimenting with other diluents to take the place of steam, but until very recently nothing satisfactory had been accomplished. Now, how ever, there are two or three plants in the course of erection upon which a new system is being tried in which the steam is replaced by a diluent consisting of cooled exhaust gases, which bids fair to answer all requirements.

The action of this substitute for steam is said to be very marked, the $\mathrm{CO}_{2}$ in the exhaust gases burnin back to CO when passing up through the fuel in the

producer, absorbing heat, while at the same time the analysis of the gas shows a higher percentage of CO,
which along with the high compression admissible is which along with the high compress
expected to offset the absence of $H$.

The special feature of the gas in this system that should recommend itself to engine builders is the fact that the analysis remains fairly constant under varying loads, and owing to the absence of hydrogen and consequent dangers from pre-ignition very high compressions should be safely carried without danger accruing therefrom.

It is expected when the installations embodying the improvements are perfected a solution may be found for the difficulties heretofore experienced.

\title{
THE PHONOCARD.
}

The phonopostal, says La Nature, is an apparatus which registers and afterward reproduces the human voice, by means of a sheet of pasteboard, shaped like a postal card. Jules Verne conceived the idea of replacing the old wax cylinder used in other phonographs by a sheet of paper, which could be posted like a letter.

The advantages of the phonopostal are numerous. The records are made by an ordinary phonograph of the simplest possible type simply by means of a stylus provided with a sapphire point. This point presses on an impressionable substance, called "sonorine," spread on the surface of the card. The merit of the invention consists in the discovery of a sul.stance which can be easily spread on a sheet of cardboard and possesses all the advantages of the waxcoated cylinders. Moreover, sonorine is able to stand the strain of transmission by mail. The sounds are inscribed in a spiral, which commences at the outside edge of the card and continues in an ever-narrowing curve until it forms a small circle, hardly the diam. eter of a small coin. The record is so deeply engraved in the coated cardboard that not more than two or three syllables are lost by the two stampings of the post office on the concentric lines.

Seventy-five or eighty words can be inscribed on a phonocard, which is sufficient for news. One object of the phonocard is to replace the illustrated postal card. Furthermore, it is possible to be far more chatty on a phonopostal than on an ordinary postal card, for on the latter there is only a little rectaigular space left which can be written on.

\section{THE CURRENT SUPPLEMENT}

The United States Geological Survey has for a number of years been studying the underground waters beneath the central great plains. The investigation is reviewed in a strikingly illustrated article which opens the current ScpplamerT, No. 1551. Mr. M. T. Cook writes on the banana. A highly instructive article is that on the spider and its web, by Maurice Koechlin. Frof. Sommer explains simply and clearly some methods which he has devised of investigating movements of expression. Sir William Crookes delivered an impressive paper on diamonds before the South African meeting of the British Association for the Advancement of Science. The first installment of the paper is published in the current Supplement. A number of extensive automobile testing laboratories have recently been fitted up in Paris. One of these is very fully described and illustrated. Mr. Walter I. Webb contributes an instructive paper on reinforced concrete, explaining its principles, with practical illustrations. "Electric Lighting for Amateurs" is the title of a lucidly-worded and fully-illustrated article describing some simple electrical work that can be carried out at home. Mr. H. Lemmoin-Cannon discusses the problem of sewage and its disposal. J. H. Long discusses the important question of protein and its relation to food.

\section{PRODUCING HIGH VACUA.}

The German scientific journal Prometheus states that the English physicist Dewar has found a new process for obtaining high vacua, which forms another practical employment of liquid air. It is known already that charcoal possesses the property in a high degree of absorbing gases. Dewar has demonstrated that this absorptive property of charcoal increases manifold if it is cooled to the temperature of liquid air (about 185). The absorption takes place so energetically that if the charcoal is contained in a closed ressel the latter soon becomes void of air. 